\title{
Non-invasive and transdermal measurement of blood uric acid level in human by electroporation and reverse iontophoresis
}

This article was published in the following Dove Press journal:

International Journal of Nanomedicine

18 November 2010

Number of times this article has been viewed

\author{
Chih-Kuei Lee' \\ Congo Tak-Shing Ching ${ }^{2-4}$ \\ Tai-Ping Sun ${ }^{2,3}$ \\ Chun-Lang Tsai ${ }^{2}$ \\ Wei Huang 5 \\ Hsin-Hung Huang ${ }^{6}$ \\ Jen-Fu Kuo ${ }^{7}$ \\ Li-Hang Lai ${ }^{6}$ \\ Mei-Ya Chien ${ }^{8}$ \\ Hsin-Hui Tseng 9 \\ Hui-Tzu Pan ${ }^{10}$ \\ Shiow-Yuan Huang ${ }^{4}$ \\ Hsiu-Li Shieh ${ }^{3}$ \\ Wei-Hao Liu ${ }^{2}$ \\ Chia-Ming Liu ${ }^{2}$ \\ Hsin-Wei Huang ${ }^{2}$
}

'Hopkins Health Management Center, Puli Christian Hospital, Nantou, Taiwan, Republic of China; ${ }^{2}$ Graduate Institute of Biomedicine and Biomedical Technology, National Chi Nan University, Nantou, Taiwan, Republic of China; ${ }^{3}$ Department of Electrical Engineering, National Chi Nan University, Nantou,

Taiwan, Republic of China; ${ }^{4}$ Department of Photonics and Communication Engineering, Asia University, Taichung, Taiwan, Republic of China; ${ }^{5}$ Division of Immunology and

Rheumatology, Puli Christian Hospital, Nantou, Taiwan, Republic of China; ${ }^{6}$ Family Medical Department, Puli Christian Hospital, Nantou, Taiwan, Republic of China; ${ }^{7}$ Division of Endocrinology and Metabolism, Puli Christian Hospital, Nantou, Taiwan, Republic of China;

${ }^{8}$ Nutrition Department, Puli Christian Hospital, Nantou, Taiwan, Republic of China; ${ }^{9}$ Aboriginal Health Care, Puli Christian Hospital, Nantou, Taiwan, Republic of China; ${ }^{10}$ Department of Medical Research and Education, Puli Christian Hospital, Nantou, Taiwan, Republic of China

Correspondence: Congo Tak-Shing Ching Graduate Institute of Biomedicine and Biomedical Technology, National Chi Nan University, No. I University Rd, Puli, Nantou County 5456I, Taiwan, Republic of China Tel +8864929 I0960 Ext 4774

Fax +886 4929 I 2434

Email tsching@ncnu.edu.tw
Abstract: The aim of this study was to find out the optimum combination of electroporation (EP) and reverse iontophoresis (RI) on noninvasive and transdermal determination of blood uric acid level in humans. EP is the use of high-voltage electric pulse to create nano-channels on the stratum corneum, temporarily and reversibly. RI is the use of small current to facilitate both charged and uncharged molecule transportation across the skin. It is believed that the combination of these two techniques has additional benefits on the molecules' extraction across the human skin. In vitro studies using porcine skin and diffusion cell have indicated that the optimum mode for transdermal uric acid extraction is the combination of RI with symmetrical biphasic direct current (current density $=0.3 \mathrm{~mA} / \mathrm{cm}^{2}$; phase duration $=180 \mathrm{~s}$ ) and EP with 10 pulses per second (voltage $=100 \mathrm{~V} / \mathrm{cm}^{2}$; pulse width $=1 \mathrm{~ms}$ ). This optimum mode was applied to six human subjects. Uric acid was successfully extracted through the subjects' skin into the collection solution. A good correlation $\left(\mathrm{r}^{2}=0.88\right)$ between the subject's blood uric acid level and uric acid concentrations in collection solutions was observed. The results suggest that it may be possible to noninvasively and transdermally determine blood uric acid levels.

Keywords: Reverse iontophoresis, electroporation, uric acid, monitoring, noninvasive, transdermal

\section{Introduction}

Gout is one of the most common forms of arthritis, ${ }^{1}$ affecting more than 700,000 adults in the $\mathrm{UK}^{2}$ and nearly three million adults in the USA, ${ }^{3}$ and accounting for almost four million outpatient visits every year, ${ }^{4}$ with a substantial economic burden. ${ }^{5}$ Excessive amounts of uric acid, known as hyperuricemia, is one of most frequent metabolism disturbances. Hyperuricemia and high mean serum uric acid concentrations as risk factors for gout have been well documented in the past decades. ${ }^{6}$ Gouty arthritis, a rapid onset of joint inflammation, is a complication of hyperuricemia and is precipitated by deposits of uric acid crystals in the synovial fluid and synovial lining. Recent research has highlighted that patients with hyperuricemia and gout are at increased risk of morbidity and mortality related to cardiovascular disease. ${ }^{7}$ Therefore, blood uric acid monitoring is very important.

The routine method to determine blood uric acid level is achieved by blood sampling. However, this method is invasive, painful, and inconvenient. To the best of our knowledge, there is no noninvasive method to determine the blood uric acid level. Therefore, reverse iontophoresis (RI) and electroporation (EP), noninvasive techniques, were used in this study to transdermally and noninvasively extract uric acid in humans. 
RI refers to the passage of a low level of current through the skin to promote the transport of both charged and neutral molecules. ${ }^{8}$ The main mechanisms that contribute to RI are the electro migration of charged species to the electrode of opposite polarity, electroosmosis of neutral molecules to the cathode or anode, or a combination of both. RI across the skin has been investigated as a noninvasive method for clinical monitoring. ${ }^{9}$ Its first clinical application was the transdermal extraction of glucose. ${ }^{10} \mathrm{EP}$ is the use of an intense electric pulse to make the cell membrane transiently porous and then permeable to exogenous molecules present in the surrounding media. ${ }^{11,12} \mathrm{EP}$ is widely used for the loading of cells with $\operatorname{drugs}^{13,14}$ and the delivery of drugs into the cells of living tissues. ${ }^{15,16}$ Recently, EP has been used for transcutaneous sampling of molecules, like glucose. ${ }^{17}$ Several papers have reported the use of combined RI and EP to enhance the effect of extracting metabolites, ${ }^{18,19}$ but no papers have been found for the use of combined RI and EP for the extraction of uric acid and this was the novelty of this study. The aim of this study was to find out the optimum combination of EP and RI on noninvasive and transdermal determination of blood uric acid level in humans.

\section{Materials and methods}

\section{Reagents and solutions}

All reagents used in this study were commercially available and used without further purification: phosphate buffered saline and uric acid were purchased from Sigma Chemical Company (St. Louis, MO) and uric acid assay kit (Catalog number: K608-100) from BioVision (Mountain View, CA).
De-ionized water, purified by a Millipore Milli-Q UFplus System (Bedford, MA) was used to prepare all solutions.

\section{Equipment}

The diffusion cell for in vitro studies was the same as previously described (Figure 1). ${ }^{20}$ The diffusion cell for human studies was newly-designed in this study, with a $5 \mathrm{~mm}$ diameter for each electrode chamber and the two electrode chambers were $11 \mathrm{~mm}$ apart (Figure 2). RI and EP devices were also newly-designed in this study. The RI device has the accuracy of $\pm 0.01 \mu \mathrm{A}$ on delivering current and $\pm 0.01 \mathrm{~ms}$ on timing. The EP device has the accuracy of $\pm 0.1 \mathrm{~V}$ on delivering voltage and $\pm 0.01 \mathrm{~ms}$ on timing. A Bio-Rad 680 microplate reader (Bio-Rad, Hemel Hempstead, UK) was used for all colorimetric analysis.

\section{Preparation of silver-silver chloride electrodes}

Silver-silver chloride $(\mathrm{Ag} / \mathrm{AgCl})$ electrodes were used in both in vitro and human studies. The $\mathrm{Ag} / \mathrm{AgCl}$ electrodes were prepared by chloridizing $99.99 \%$ pure silver wire, $1 \mathrm{~mm}$ in diameter and $25 \mathrm{~mm}$ in length (Aldrich Chemical Company Inc, Milwaukee, WI), immersed in $0.1 \mathrm{M} \mathrm{HCl}$ solution (Pt-cathode) for 90 minutes at an applied current of $314 \mu \mathrm{A}$.

\section{In vitro studies}

All experiments were conducted using diffusion cells, in which both electrode chambers were located on the same surface side of a porcine skin $(250 \mu \mathrm{m})$ obtained by



Figure I Diffusion cell for in vitro studies. 


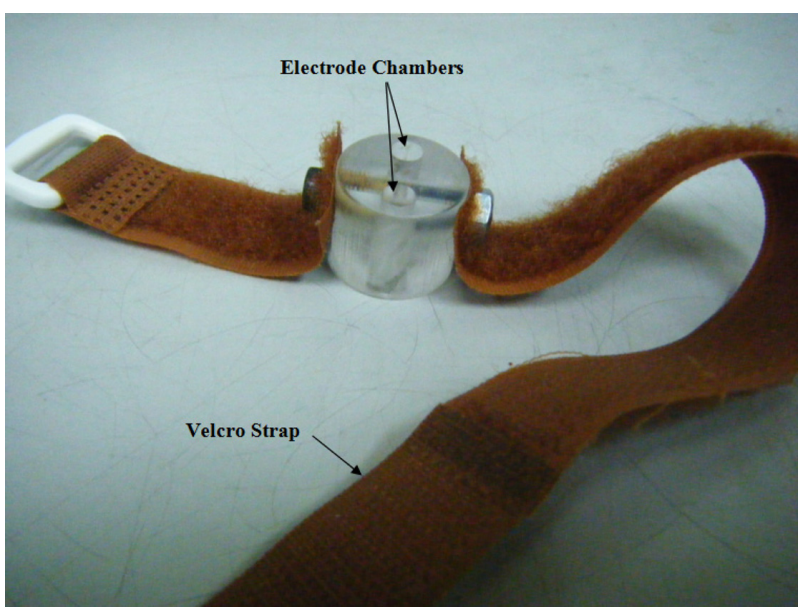

Figure 2 Diffusion cell (diameter $=27 \mathrm{~mm}$ ) for human studies. Each electrode chamber had a diameter of $5 \mathrm{~mm}$ and they were $1 \mathrm{I} \mathrm{mm}$ apart.

dermatome. Both the electrode chambers and the lower chamber of the diffusion cell were filled with $0.1 \mathrm{M}$ phosphate buffer ( $\mathrm{pH}$ 7.0) while the lower chamber additionally contained $416 \mu \mathrm{M}$ uric acid. Each electrode chamber contained a $\mathrm{Ag} / \mathrm{AgCl}$ electrode. The surface area of the porcine skin exposed to the electrode in each chamber was $0.2 \mathrm{~cm}^{2}$ and the electrode chambers were $11 \mathrm{~mm}$ apart. Different modes of EP and RI (Table 1 and Figure 3) were applied via the $\mathrm{Ag} / \mathrm{AgCl}$ electrodes. The entire content of the electrode chambers were removed at the end of the experiment to determine the amount of uric acid extracted.

\section{Human studies}

Six subjects (four men and two women; mean age $45 \pm$ 13 years) were recruited in this study. The study was approved by The Institutional Review Board of National Chi Nan University. Informed consent was obtained from each subject before the experiment.

The areas of skin of the subject's outer forearm where diffusion cell was to be located were prepared by briskly rubbing the areas for $6-8 \mathrm{~s}$ with alcohol preparation pads to remove dry skin, oils, and other contaminants. The areas were then allowed to dry thoroughly. Once the diffusion cell and $\mathrm{Ag} / \mathrm{AgCl}$ electrodes were fixed in position onto the human forearm, $300 \mu \mathrm{l}$ phosphate buffer (0.1 M; pH 7.0) was added into each electrode chamber of the diffusion cell. Then, the optimum combination of RI (symmetrical biphasic direct current (dc) with the current density of $0.3 \mathrm{~mA} / \mathrm{cm}^{2}$ and the phase duration of $180 \mathrm{~s})$ and EP $\left(100 \mathrm{~V} / \mathrm{cm}^{2}\right.$ electric pulse with the pulse width of $1 \mathrm{~ms}$ and 10 pulses per second) was applied via the $\mathrm{Ag} / \mathrm{AgCl}$ electrodes to the human skin. At the end of the experiment, phosphate buffer was pipetted from the electrode chambers and stored in microcentrifuge tubes at $4^{\circ} \mathrm{C}$ for later quantification of uric acid. The subject's blood uric acid level was also measured before experiments at the central laboratory of the Puli Christian Hospital.

\section{Determination of the extracted uric acid}

Colorimetric assay was used to determine the amount of uric acid extracted through the porcine or human skin during the in vitro and human studies. An excellent linear relationship $\left(r^{2}>0.9\right)$ between uric acid concentrations and its relative absorbance was found, allowing the uric acid concentration to be calculated simply by linear regression.

\section{Statistical analysis}

One-way ANOVA was used to determine whether there were significant differences between EP parameters within a RI parameter, and between RI parameters within an EP parameter for the uric acid extraction. Post hoc comparisons were made with independent samples $t$-tests. A linear regression test was used to determine the relationship between the subject's blood uric acid level and uric acid concentrations in collection solutions. All statistical analyses were carried out using SPSS software (SPSS Inc., Chicago, IL), with the level of statistical significance set at $P<0.05$.

\section{Results and discussion In vitro studies}

In this study, 195 combinations of RI and EP were chosen for the transdermal uric acid extraction in order to find out the optimum combination of EP and RI on noninvasive and transdermal determination of blood uric acid level in humans.

Uric acid is a negatively-charged molecule and its molecular weight is about $168 \mathrm{Da}$. Because of its small size and negative charge, uric acid was expected to be transdermally extractable. Electromigration was expected to be the dominant physical factor for the uric acid extraction.

As shown in Figure 4, the application of RI, EP, or the combination of both could facilitate a higher uric acid extraction as compared to diffusion alone. It was found that the uric acid extraction increased as the phase duration of the symmetrical biphasic dc (PDSBdc) increased. At $50 \mathrm{~V} / \mathrm{cm}^{2}$, $100 \mathrm{~V} / \mathrm{cm}^{2}$, and $150 \mathrm{~V} / \mathrm{cm}^{2} \mathrm{EP}$, uric acid extraction using the $180 \mathrm{~s}$ PDSBdc was found to be significantly higher ( $P<0.001$ in all cases) than that of protocols utilizing $0 \mathrm{~s}$, $15 \mathrm{~s}$, and $30 \mathrm{~s}$ PDSBdc conditions. Although an independent samples $t$-test revealed no significant difference $(P=0.617)$ between uric acid extraction using the $60 \mathrm{~s}$ and $180 \mathrm{~s}$ PDSBdc, 
Table I Experimental protocol for the in vitro studies

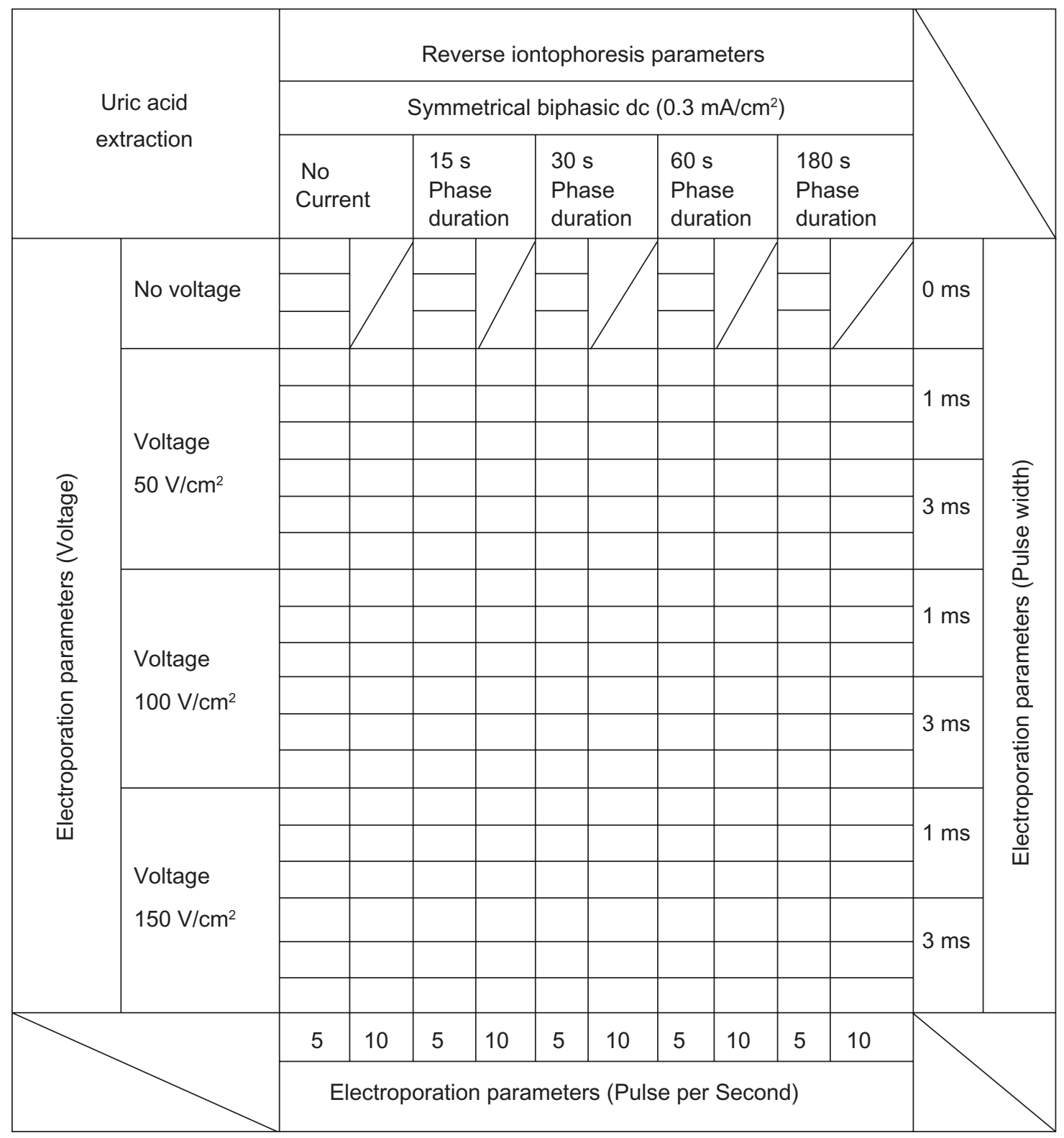

Notes: One hundred ninety five different combinations of reverse iontophoresis and electroporation parameters were selected for the in vitro transdermal uric acid extraction, in order to determine the optimum combination for uric acid extraction.

it was observed that the longer the PDSBdc, the better the uric acid extraction was. Therefore, $180 \mathrm{~s}$ PDSBdc was recommended as the optimum setting. On the other hand, the combination of RI and EP could facilitate a higher uric acid extraction as compared to RI or EP alone. This was because EP could create reversible nanochannels on the $\operatorname{skin}^{10,11}$ and this could further facilitate the uric acid extraction as compared with RI alone. It was also found that the higher the voltage of the EP, the better the uric acid extraction was. This meant that $150 \mathrm{~V} / \mathrm{cm}^{2} \mathrm{EP}$ was better than $50 \mathrm{~V} / \mathrm{cm}^{2} \mathrm{EP}$ $(P<0.001$ in all cases of $15 \mathrm{~s}, 30 \mathrm{~s}, 60 \mathrm{~s}$, and $180 \mathrm{~s}$ PDSBdc $)$, as $150 \mathrm{~V} / \mathrm{cm}^{2} \mathrm{EP}$ had relatively more energy to effectively create more nanochannels. On the other hand, there was no significant difference $(P=0.413)$ between the $100 \mathrm{~V} / \mathrm{cm}^{2} \mathrm{EP}$ and $150 \mathrm{~V} / \mathrm{cm}^{2} \mathrm{EP}$ on the uric acid extraction. $100 \mathrm{~V} / \mathrm{cm}^{2} \mathrm{EP}$ was therefore recommended as the optimum setting. Also, no significant difference $(P=0.552)$ was found between $1 \mathrm{~ms}$ and $3 \mathrm{~ms}$ pulse width of the EP on the uric acid extraction. As such, a $1 \mathrm{~ms}$ pulse width of the EP was recommended as the optimum setting because $1 \mathrm{~ms}$ pulse width was commonly used in clinic. Moreover, EP with 10 pulses per second facilitated significantly more uric acid extraction $(P<0.05)$ as compared with EP with 5 pulses per second. Therefore, EP with 10 pulses per second was recommended as the optimum setting. In a nutshell, the optimum combination of RI and EP on uric acid extraction was as follows: 

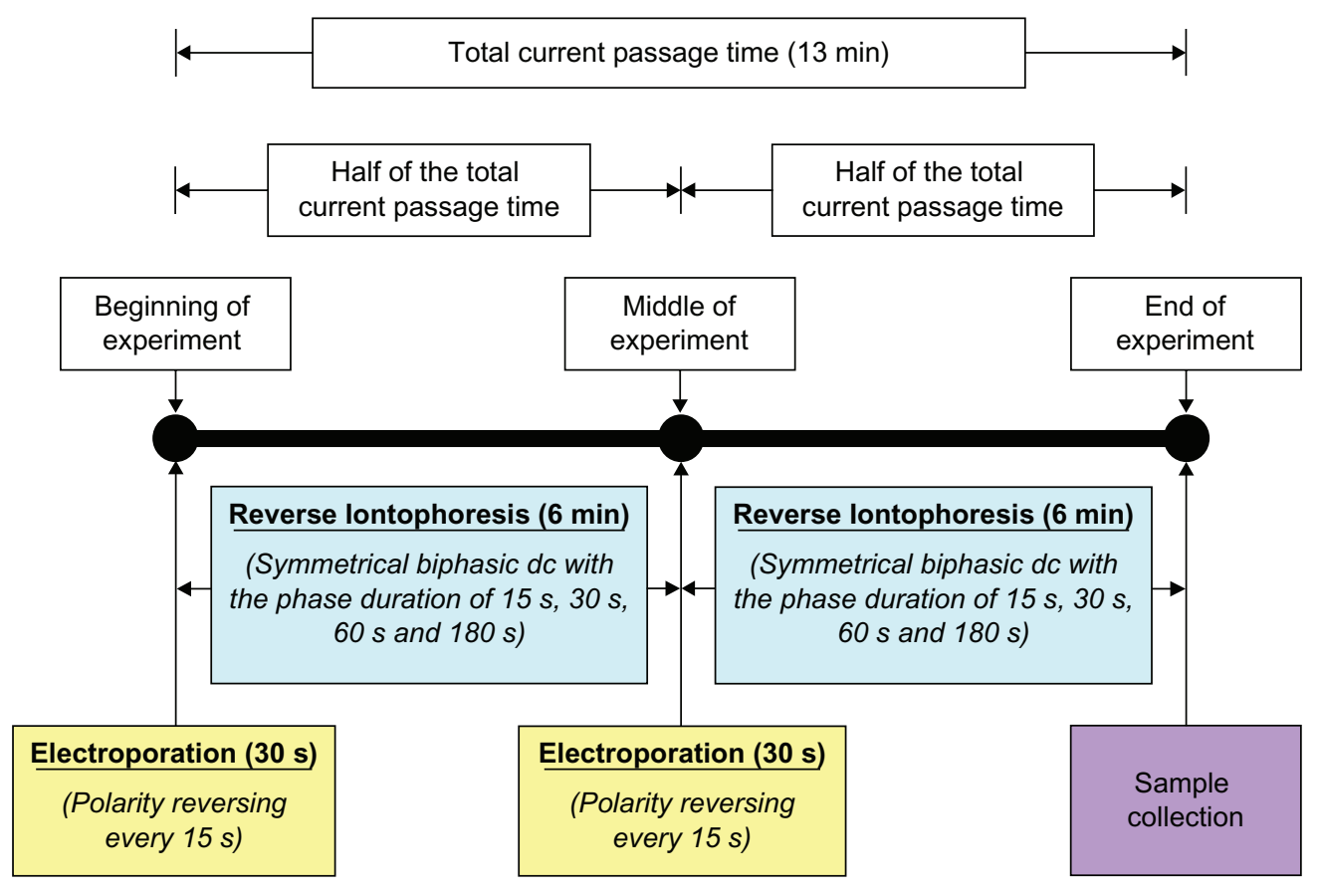

Figure 3 Experimental protocol showing the time sequence for the application of electroporation, reverse iontophoresis, and sample collection.

- RI: symmetrical biphasic de with a current density of $0.3 \mathrm{~mA} / \mathrm{cm}^{2}$ and a phase duration of $180 \mathrm{~s}$

- EP: $100 \mathrm{~V} / \mathrm{cm}^{2}$ electric pulse with a pulse width of $1 \mathrm{~ms}$ and 10 pulses per second.

\section{Human studies}

No erythema was observed on any subject's skin after the application of RI and EP. In addition, no subject reported pain or even unpleasant feeling during or after the experiment. Therefore, this human study demonstrated that RI and EP could provide a safe, painless, and non invasive extraction of uric acid in humans.

In this human study, the combination of RI and EP significantly promoted transdermal uric acid extraction, but there are no other human studies for data comparison. As shown in Figure 5, a good correlation $\left(r^{2}=0.88\right)$ between the subject's blood uric acid level and uric acid concentrations in collection solutions was observed. This meant that the subject's blood uric acid level could be predicted by the uric acid concentrations in collection solutions using the linear regres-


Phase duration of the symmetrical biphasic dc

Uric acid extraction by:

$1 \mathrm{~ms} P W \approx 3 \mathrm{~ms} P W(P=0.552)$

. $10 \mathrm{P} / \mathrm{s}>5 \mathrm{P} / \mathrm{s}(P<0.05)$

Figure 4 In vitro studies of the transdermal and noninvasive extraction of uric acid by different combinations of reverse iontophoresis (RI) and electroporation (EP). For the $\mathrm{RI}$ setting, it was a symmetrical biphasic dc with the current density of $0.3 \mathrm{~mA} / \mathrm{cm}^{2}$. The legend shows the electroporation setting where $\mathrm{PW}$ and $\mathrm{P} / \mathrm{s}$ are the pulse width and pulse per second of the electroporation, respectively. 


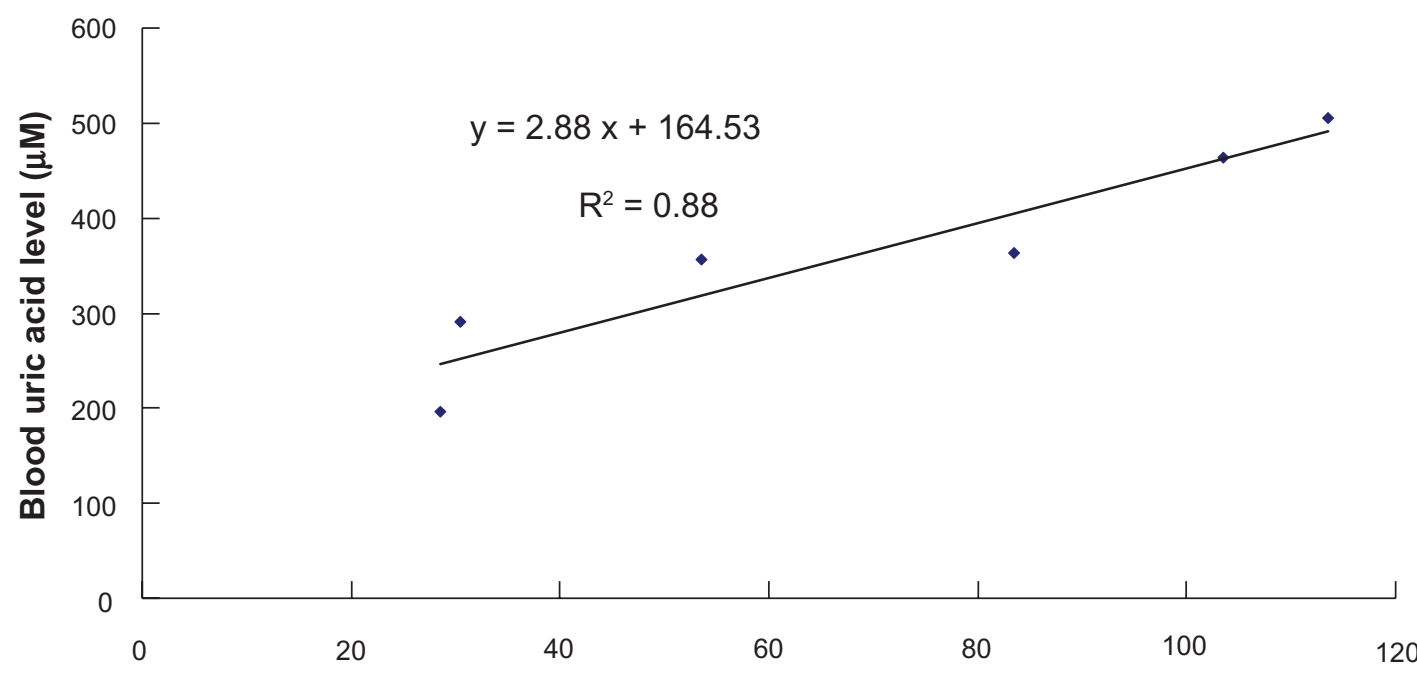

Uric acid concentration in the collection solution $(\mu \mathrm{M})$

Figure 5 Comparison of real blood uric acid levels of subjects and uric acid concentrations in the collection solution after the application of the optimum combination of reverse iontophoresis and electroporation.

sion equation. Therefore, a transdermal and noninvasive method for blood uric acid monitoring was established.

Despite promising early results, the correlation between the subject's blood uric acid level and uric acid concentration in the collection solution was still not too high. Hence, it is necessary to test this method using larger subject groups in order to achieve a better correlation between the subject's blood uric acid level and uric acid concentration in the collection solution. On the other hand, subjects with a large difference of blood uric acid level are expected to improve the correlation as well.

\section{Conclusion}

Uric acid could be transdermally and noninvasively extracted by the combination of RI and EP. The optimum mode was the combination of the RI with symmetrical biphasic dc (current density $=0.3 \mathrm{~mA} / \mathrm{cm}^{2}$; phase duration $=180 \mathrm{~s}$ ) and EP with 10 pulses per second (voltage $=100 \mathrm{~V} / \mathrm{cm}^{2}$; pulse width $=1 \mathrm{~ms})$. A good correlation between the subject's blood uric acid level and uric acid concentrations in collection solutions was observed. Therefore, a transdermal and noninvasive method for blood uric acid monitoring was established.

\section{Acknowledgments}

The authors would like to thank the six subjects who participated in this study. This work was supported by grants (98A032) from the National Chi Nan University and Puli Christian Hospital, Taichung, Taiwan, Republic of China. This work was also partially supported by grants (NSC 99-2221E-260-004- and NSC 98-2221-E-260-024-MY3) from the National Science Council, Taiwan, Republic of China.

\section{Disclosure}

The authors report no conflicts of interest in this work.

\section{References}

1. Choi HK, Mount DB, Reginato AM. Pathogenesis of gout. Ann Intern Med. 2005;143:499-516.

2. Mikuls TR, Farrar JT, Bilker WB, Fernandes S, Schumacher HR, Saag KG. Gout epidemiology: results from the UK General Practice Research Database, 1990-1999. Ann Rheum Dis. 2005;64:267-272.

3. Lawrence RC, Felson DT, Helmick CG. Estimates of the prevalence of arthritis and other rheumatic conditions in the United States. Arthritis Rheum. 2008;58:26-35.

4. Krishnam E, Lienesch D, Kwoh CK. Gout in ambulatory care setting in the United States. J Rheumatol. 2008;35:498-501.

5. Wu EQ, Patel PA, Yu AP. Disease-related and all-cause health care costs of elderly patients with gout. J Manag Care Pharm. 2008;14: 164-175.

6. Glynn RJ, Campion EW, Silbert EJ. Trends in serum uric acid levels 1961-1980. Arthritis Rheum. 1983;26:87-93.

7. Edwards NL. The role of hyperuricemia and gout in kidney and cardiovascular disease. Cleve Clin J Med. 2008;75 Suppl 5:S13-S16.

8. Merino V, Kalia YN, Guy RH. Transdermal therapy and diagnosis by iontophoresis. Trends Biotechnol. 1997;15:288-290.

9. Leboulanger B, Guy RH, Delgado-Charro MB. Reverse iontophoresis for non-invasive transdermal monitoring. Physiol Meas. 2004;25: R35-R50.

10. Guy RH. A sweeter life for diabetics. Nat Med. 1995;1:1132-1133.

11. Neumann E, Schaefer-Ridder M, Wang Y, Hofschneider PH. Gene transfer into mouse lyoma cells by electroporation in high electric field. EMBO J. 1982;7:841-845.

12. Chang DC, Chassy BM, Saunders JA, Sowers AE, editors. Guide to Electroporation and Electrofusion. San Diego, CA: Academic Press Inc; 1992. 
13. Zimmermann U, Vienken J, Pilwat G. Development of drug carrier systems: Electrical field induced effects in cell membranes. Bioelectrochem Bioenerg. 1980;7:553-574.

14. Sixou S, Teissié J. Specific electropermeabilization of leucocytes in a blood sample and application to large volumes of cells. Biochem Biophys Acta. 1990;1028:154-160.

15. Okino M, Mohri H. Effects of a high-voltage electrical impulse and an anticancer drug on in vivo growing tumors. Jpn J Cancer Res. 1987;78:1319-1321.

16. Mir LM, Orlowski S, Belehradek J Jr, Paoletti C. In vivo potentiation of the bleomycin cytotoxicity by local electric pulses. Eur J Cancer. 1991;27:68-72.
17. Srinivasa Murthy S, Siva Ram Kiran V, Mathur S, Narasimha Murthy S. Noninvasive transcutaneous sampling of glucose by electroporation. J Diabetes Sci Technol. 2008;2:250-254.

18. Jadoul A, Bouwstra J, Preat V. Effect of iontophoresis and electroporation on the stratum corneum. Adv Drug Deliv Rev. 1999;35:89-105.

19. Tokumoto S, Higo N, Sugibayashi K. Effect of electroporation and $\mathrm{pH}$ on the iontophoresis transdermal delivery of human insulin. Int $J$ Pharm. 2006;326:13-19.

20. Ching CTS, Connolly P. Reverse iontophoresis: A non-invasive technique for measuring blood lactate level. Sensor Actuat B-Chem. 2008;129:352-358.
International Journal of Nanomedicine

\section{Publish your work in this journal}

The International Journal of Nanomedicine is an international, peerreviewed journal focusing on the application of nanotechnology in diagnostics, therapeutics, and drug delivery systems throughout the biomedical field. This journal is indexed on PubMed Central, MedLine, CAS, SciSearch ${ }^{\circledR}$, Current Contents ${ }^{\circledR} /$ Clinical Medicine,

\section{Dovepress}

Journal Citation Reports/Science Edition, EMBase, Scopus and the Elsevier Bibliographic databases. The manuscript management system is completely online and includes a very quick and fair peer-review system, which is all easy to use. Visit http://www.dovepress.com/ testimonials.php to read real quotes from published authors.

Submit your manuscript here: http://www.dovepress.com/international-journal-of-nanomedicine-journal 